\title{
Effect of Heat Treatment on Tensile and Corrosion Properties of LM6 Hybrid Metal Matrix Composite Reinforced with Cenosphere and Red Mud
}

\author{
Ravi Kumar V.1, Suresh R. ${ }^{2}$, Prakash Rao C. R. ${ }^{1}$, Ravi Kumar D. V.1, Bharat V.1 \\ ${ }^{1}$ Department of Mechanical Engineering, Global Academy of Technology, Bengaluru, India \\ ${ }^{2}$ Department of Industrial \& Automation Engineering, VTU PG Centre, Mysuru, India \\ Email:vrkgat2007@gmail.com
}

How to cite this paper: Ravi Kumar V., Suresh R., Prakash Rao C. R., Ravi Kumar D. V. and Bharat V. (2019) Effect of Heat Treatment on Tensile and Corrosion Properties of LM6 Hybrid Metal Matrix Composite Reinforced with Cenosphere and Red Mud. Journal of Minerals and Materials Characterization and Engineering, 7, $1-17$.

https://doi.org/10.4236/jmmce.2019.71001

Received: October 16, 2018

Accepted: December 11, 2018

Published: December 17, 2018

Copyright $\odot 2019$ by authors and Scientific Research Publishing Inc. This work is licensed under the Creative Commons Attribution International License (CC BY 4.0).

http://creativecommons.org/licenses/by/4.0/ CC) (i) Open Access

\begin{abstract}
The increased expectation of automotive, aviation and marine industries pertaining to the enhanced properties and their use in elevated temperature conditions and also corrosive environments leads to the development of the newer material to meet the requirements. The requirements of the automobile and marine applications call for the increased mechanical properties and lower density accompanied with higher resistance to oxidation. Hence the present research work is aimed at the development of Hybrid metal matrix composites (HMMCs) using low-density base material and reinforcements. The aluminum of grade LM6 is preferred material in automobile industries, because it can be cast to any complex geometry and possess good machinability, further upon heat treatment, the properties of LM6 alloy can be enhanced to meet the industry requirements. However, requirements of automobile industries consist of increased mechanical properties, lower density and higher corrosion resistance. Hence, in the present research work, it is aimed to develop newer composite material using LM 6 grade Aluminum alloy as matrix material which is reinforced with varied percent Cenosphere and Red mud.
\end{abstract}

\section{Keywords}

LM6 Alloy, Cenosphere, Red Mud, HMMCs, Tensile Test, $\mathrm{NaCl}$, NaOH, Salt Spray Test, Immersion Corrosion Test

\section{Introduction}

Hybrid metal matrix composites are preferred materials for automobile, engi- 
neering, sports and consumer-oriented products owing to their strength to weight ratio. Stir casting method was used to fabricate Aluminum metal matrix composites by earlier researchers using fly ash, cenosphere, beryllium powder as reinforcements [1]-[6]. Increase in hardness of the composite materials was observed when the reinforcement was added to the matrix material [7] [8] [9]. The density of the aluminum metal matrix composites containing fly ash as reinforcement found lower when compared to the base material [10]. Improvement in bonding of the reinforcement with the matrix material was observed when the composites were sintered at $600^{\circ} \mathrm{C}$ [11]. The microstructural analysis revealed that the distribution of the reinforcement material in the matrix was uniform [12]. The results of the images revealed that the secondary phase particles as well as the existence of microvoids at the interface of the matrix and reinforcement [13]. The SEM analysis revealed that the reinforcement particle was dispersed in the matrix uniformly, however tiny clusters and empty spaces were observed at some places [14]. Tensile strength and percent elongation of the AA7075 grade aluminum alloy reinforced with $\mathrm{TiC}$ was found higher when compared to base material [15]. Increased hardness and tensile strength of the redmud reinforced aluminum metal matrix composite was observed when compared to the base material [16]. The hardness and tensile strength of aluminum hybrid metal matrix composites reinforced with cenosphere and graphite were found higher when compared to base material [17]. Addition of silicon carbide particles resulted in higher tensile strength and yield strength, further heat treatment of composites resulted in increased tensile strength [18]. Heat treated and aged composites have shown higher hardness and higher ultimate strength when compared to base material [19]. Increased ultimate tensile strength, yield strength and elongation was observed on T6 heat treated LM26 aluminum-silicon alloy when compared to untreated LM26 aluminum-silicon alloy [20]. Aluminum bronze samples showed discoloration when subjected to $\mathrm{NaOH}$ and $\mathrm{H}_{2} \mathrm{SO}_{4}$ solution. The increased corrosion rate was observed with higher $\mathrm{H}_{2} \mathrm{SO}_{4}$ and $\mathrm{NaCl}$ solutions, but oxidations found more aggressive with $\mathrm{HCl}$ solution [21]. Al-Mg-Si matrix containing rice husk ash and silicon carbide particles were shown improved corrosion resistant when subjected to $3.5 \% \mathrm{NaCl}$ solution [22]. Al6063 grade aluminum alloy reinforced with $\mathrm{Al}_{2} \mathrm{O}_{3}$ particulates have shown good corrosion resistance in $\mathrm{NaCl}$ solution than $\mathrm{NaOH}$ and $\mathrm{H}_{2} \mathrm{SO}_{4}$ solutions. The heat treated composite material shown higher corrosion resistance when compared to untreated composite material [23]. The increased percentage of frit in the Al6061 matrix shown increased corrosion resistance and corrosion rate of heat-treated composites found lower than untreated composites [24]. The results of the experiments shown that when the material was subjected to overloads and corrosive environment the fatigue life reduced due to corrosion pit formation, anodic dissolution and hydrogen embrittlement [25].

The above review revealed that less research work was done on the effect of heat treatment on tensile and corrosion properties of LM6 hybrid metal matrix 
composite reinforced with varied percent Cenosphere and Red mud. Hence, aim of the research work was to investigate the effect of solution heat treatment on tensile and corrosion properties of LM6 hybrid metal matrix composite reinforced with varied percent Cenosphere and Red mud.

\section{Materials and Method}

\subsection{Materials}

The base material used for the research work was LM6 grade Aluminum-siliconalloy consists of $12 \%$ silicon. The chemical composition of Aluminum alloy used for the investigation is presented in Table 1. The LM6 grade aluminum alloy used for the experiment is shown in Figure 1. The reinforcement materials used for the research work consists of the extracts of the fly ash which is cenospheres and another reinforcement material used for research work was the byproduct obtained from the bayers process which is red mud. The chemical composition of the cenospheres and red mud reinforcements are presented in Table 2 and Table 3 respectively. The cenospheres used for the experimentation was of a diameter range of 106 to 140 microns and particle size of red mud measured was 40 microns. The reinforcements used to fabricate HMMCs is shown in Figure 2 and Figure 3.

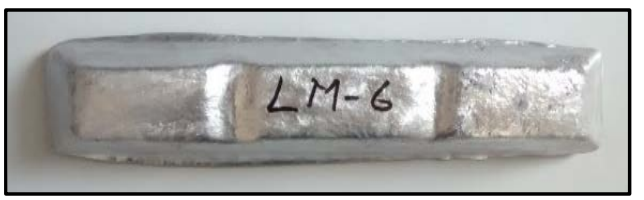

Figure 1. LM6 grade Aluminum alloy used for the experiment.

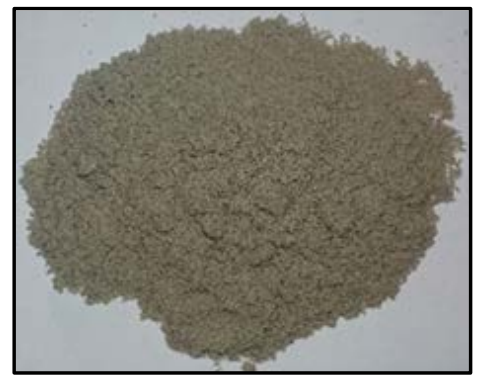

Figure 2. Cenosphere used for the preparation of HMMCs

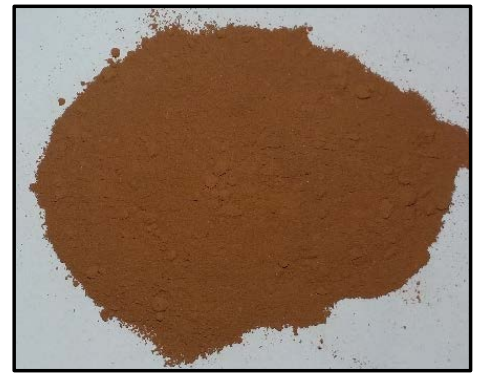

Figure 3. Red mud used for the preparation of HMMCs. 
Table 1. Component percent of LM6 grade Aluminum silicon alloy.

\begin{tabular}{ccccccc}
\hline Parameter & Silicon & Ferrous & Manganese & Copper & Nickel & Aluminum \\
\hline Percent weight & 11.61 & 0.34 & 0.36 & 0.06 & 0.06 & Remainder \\
\hline
\end{tabular}

Table 2. Component percent of cenosphere.

\begin{tabular}{cccccc}
\hline Parameter & $\begin{array}{c}\text { Silicon } \\
\text { dioxide }\end{array}$ & $\begin{array}{c}\text { Aluminum } \\
\text { oxide }\end{array}$ & $\begin{array}{c}\text { Calcium } \\
\text { oxide }\end{array}$ & $\begin{array}{c}\text { Magnesium } \\
\text { oxide }\end{array}$ & $\begin{array}{c}\text { Iron } \\
\text { oxide }\end{array}$ \\
\hline Percent weight & 56.28 & 32.1 & 2.44 & 2.11 & 6.7 \\
\hline
\end{tabular}

Table 3. Component percent of red mud.

\begin{tabular}{ccccccc}
\hline Parameter & Ironoxide & $\begin{array}{c}\text { Aluminum } \\
\text { oxide }\end{array}$ & Silica & $\begin{array}{c}\text { Titanium } \\
\text { oxide }\end{array}$ & $\begin{array}{c}\text { Calcium } \\
\text { oxide }\end{array}$ & LOI \\
\hline Percent weight & 42.03 & 20.4 & 14.43 & 7.52 & 1.46 & 11.54 \\
\hline
\end{tabular}

\subsection{Fabrication of HMMCs Material}

The LM6 grade Aluminum alloy was the base material chosen for preparing the HMMCs. The hardness, density and chemical composition of the base metal was verified before further processing. The base material was cut into $20 \mathrm{~mm}$ length from the ingot and then weighed using the physical balance. The cut LM6 pieces are stacked in the graphite crucible and then heated to attain melting temperature using an electric induction furnace. The electric induction furnace and the stirring mechanism used to fabricate HMMCs are shown in Figure 4(a). The permanent mold used to fabricate the HMMCs is shown in the Figure 4(b), and the permanent mold of diameter $30 \mathrm{~mm}$ and length $300 \mathrm{~mm}$ was heated to about $400^{\circ} \mathrm{C}$ in order to eliminate the sudden cooling of the molten HMMCs material. Degassing of entrapped gases were carried out by the addition of hexachloroethane tablets to the molten bath. Further, the slag inclusion was taken away from the molten bath after degassing process and the then the reinforcements were introduced following the stirring technique, and the same is shown in Figure 4(a). The measured quantity of the reinforcements was added to the molten bath following rule of mixtures while stirring of the molten material in order to obtain even distribution of reinforcements in the HMMCs. After, completion of the stirring process the molten mixture was poured into the preheated permanent mold in order to obtain HMMCs. After 20 hours of cooling in the mold the HMMCs were taken and subjected to thorough cleaning process and any fins and blisters were removed before further processing.

\subsection{Heat Treatment of Composite Material}

Composite material containing varied percent cenosphere and $2 \%$ red mud content was heat treated following $\mathrm{T} 6$ heat treatment process. The heat treatment process consists of solutionizing and aging. The solutionizing process was carried out at $460^{\circ} \mathrm{C}$ and then quenched in cold water, further aging process was carried out at $125^{\circ} \mathrm{C}$. 


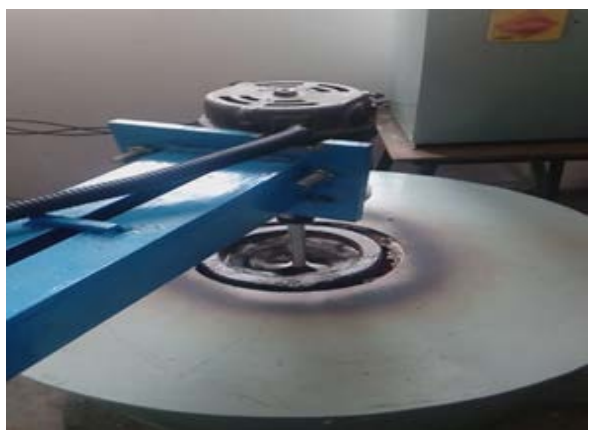

(a)

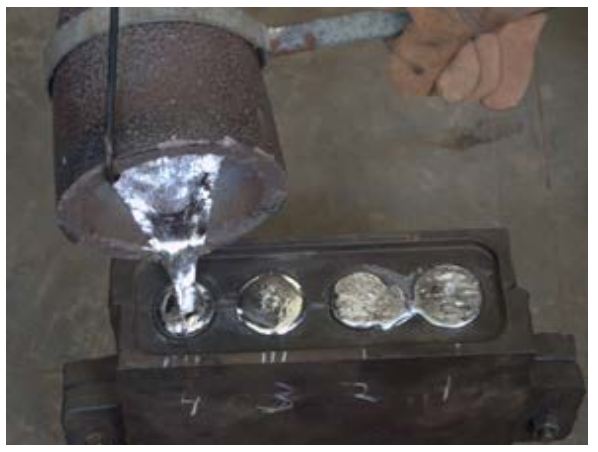

(b)

Figure 4. (a) Electric induction furnace and the stirring mechanism used to fabricate composite; (b) the permanent mould used to fabricate composite.

\section{Experimental Details}

\subsection{Hardness Test}

The Brinell hardness test of the LM6 HMMCs specimens were carried out as per ASTM E10 standard on $\mathrm{KB} 3000 \mathrm{H}$ model Brinell hardness tester and the same is shown in Figure 5. The hardness of the varied percent cenosphere and $2 \%$ red mud reinforced LM6 HMMCs were measured using $10 \mathrm{~mm}$ steel ball indenter.

\subsection{Density of the HMMCs}

The density of the LM6 hybrid metal matrix composite material reinforced with cenosphere and red mud was carried out using both theoretical and experimental techniques. The theoretical and experimental density values for $0 \%-8 \%$ cenosphere in steps of $2 \%$, while maintaining $2 \%$ red mud constant.

\subsection{Tensile Test}

Tensile test of the newly developed HMMCs was carried out on Model UTK 40, Universal Testing Machine. The cast specimens containing varied percent reinforcement materials were machinedas per ASTM E8 Standard.

\subsection{Corrosion Test}

The experiments on the corrosion properties of the HMMCs were carried out following ASTM B117, ASTM G31 standards, the testing methods adopted for 
evaluating corrosion properties were salt spray test on $\mathrm{NaCl}$ and immersion corrosion test using $\mathrm{NaCl}$ and $\mathrm{NaOH}$ solution in order to replicate the rusting which occurs naturally.

\subsubsection{The Salt Spray Corrosion Test}

The Salt spray corrosion test was conducted to HMMCs for 24 hours and it was observed that the corrosion rate found negligible, however, the rate of corrosion of the composites containing $8 \%$ cenosphere found marginally high.

\subsubsection{Immersion Corrosion Test}

As cast and solution heat treated specimens were subjected to two different corrosion environments. The specimens used for the corrosion experiments were prepared following standard procedures. The HMMCs specimens were subjected to the immersion corrosion test and loss of material as a result of corrosion for every specimen was evaluated as per ASTM G31 standards. The immersion corrosion test set up containing $5 \mathrm{wt} \% \mathrm{NaCl}$ Solution is shown in Figure 6.

\section{1) Corrosion Behavior in $5 \mathrm{wt} \% \mathrm{NaCl}$ Solution}

The immersion corrosion test was carried out using $5 \mathrm{wt} \% \mathrm{NaCl}$ solution for 30 days, maintaining an equal interval of 5 days. Samples were cleaned using standard cleaning reagent followed by rinsing in distilled water, before immersing the specimens in the $5 \mathrm{wt} \% \mathrm{NaCl}$ salt solutions. The mass loss of specimens as a result of immersion corrosion test was evaluated for both as cast and solution heat treated specimens containing varied percent reinforcement.

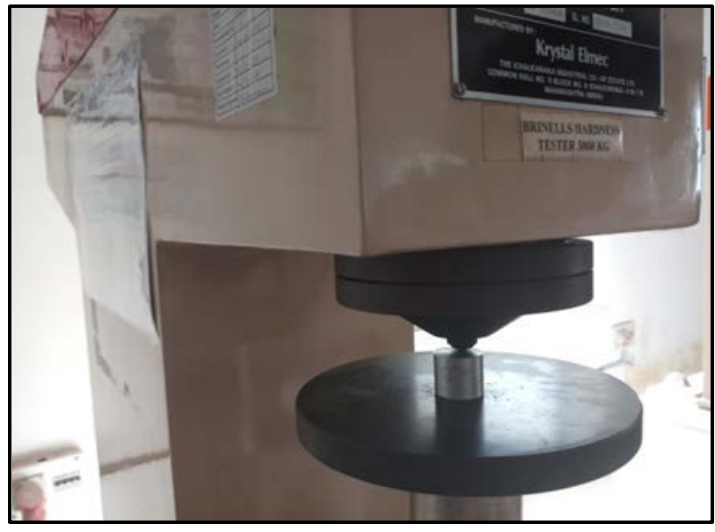

Figure 5. Measurement of the hardness of HMMCs.

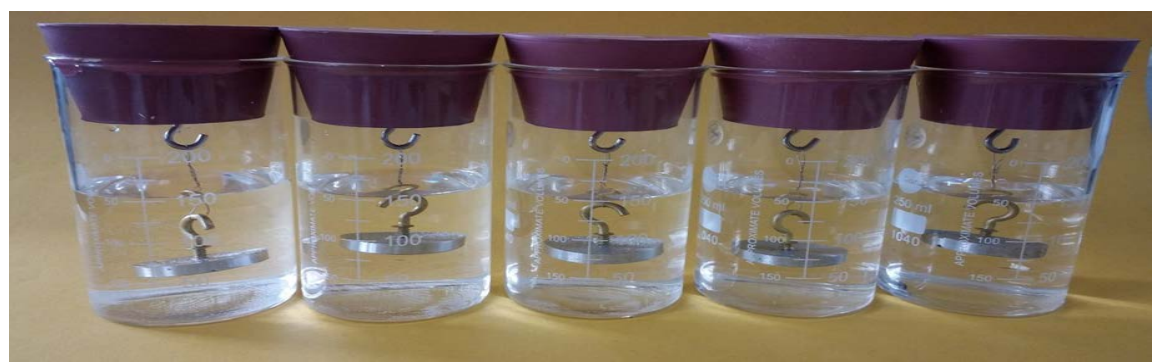

Figure 6. Immersion corrosion test setup containing $5 \mathrm{wt} \% \mathrm{NaCl}$ Solution. 


\section{2) Corrosion Behavior in $0.1 \mathrm{M} \mathrm{NaOH}$ Solution}

The immersion corrosion experiments were carried out to study corrosion behavior of LM6 HMMCs between 6 to 48 hours duration, maintaining an interval of 6 hours. Samples were cleaned using standard cleaning reagent followed by rinsing in distilled water, before immersing the specimens in the $0.1 \mathrm{M} \mathrm{NaOH}$ solution. The mass loss of HMMCs specimens were evaluated for both as cast and solution heat treated specimens containing varied percent reinforcement.

\subsection{Microstructural Studies}

The specimens were subjected to microstructural study to analyze the presence and distribution of the reinforcement. Scanning Electron microscope of model VEGA3 and make TESCAN where used for the microstructural analysis of HMMCs.

\section{Results \& Discussion}

\subsection{Measurement of Hardness}

The hardness of the HMMCs was carried out at a load of $500 \mathrm{~kg}$ and an average of 10 indentations was considered to assess the hardness of the HMMCs. The measured hardness values of a composite material containing varied percent reinforcement of both solution heat treated and untreated are tabulated in Table 4. The influence of percent reinforcement and solution heat treatment on Brinell hardness number of the HMMCs are discussed in Figure 7.

From Figure 7, it can be inferred that as the increase of reinforcement leads to the increase of hardness of the HMMCs material and the increase of the hardness follows an ascending order. The hardness of solution heat treated composites found higher when compared to untreated composites.

\subsection{Density}

The density of the HMMCs was measured using the experimental technique and also calculated using the rule of mixtures are tabulated in Table 5 and the same is presented in Figure 8.

From Figure 8, it is clear that the density of the HMMCs is lower than the base material. It is attributed to the fact that the density of the cenosphere is lower than the LM6 grade aluminum alloy. Further, the theoretical and experimental density values align with each other, which indicated the method adopted for the fabrication of the HMMCs is reliable.

\subsection{Tensile Test}

The specimen used for the tensile test is shown in Figure 9. The results of the tensile test is presented in Figure 10. From Figure 10, it can be concluded that, as percent reinforcement increases the ultimate tensile strength decreases and the ultimate tensile strength found least with the composite containing 8 percent cenosphere and 2 percent Red mud. 
Table 4. Hardness of solution heat treated and untreated composites.

\begin{tabular}{ccccc}
\hline & Cenosphere & Red mud & Untreated & Heat treated \\
\hline Sample 1 & 0 & 0 & 62.55 & 70.04 \\
Sample 2 & 2 & 2 & 64.64 & 72.39 \\
Sample 3 & 4 & 2 & 66.83 & 76.84 \\
Sample 4 & 6 & 2 & 69.14 & 82.52 \\
Sample 5 & 8 & 2 & 71.70 & 86.65 \\
\hline
\end{tabular}

Table 5. Theoretical and experimental density values of HMMCs.

\begin{tabular}{|c|c|c|c|c|}
\hline \multirow{2}{*}{$\begin{array}{c}\text { Sample } \\
\text { Designation }\end{array}$} & \multicolumn{2}{|c|}{ Percentage Reinforcement } & \multirow{2}{*}{$\begin{array}{l}\text { Density as per rule of } \\
\text { mixture in } \mathrm{g} / \mathrm{cc}\end{array}$} & \multirow{2}{*}{$\begin{array}{c}\text { Density ads per } \\
\text { Archimedes principle in } \mathrm{g} / \mathrm{cc}\end{array}$} \\
\hline & Cenosphere & Red mud & & \\
\hline Sample 1 & 0 & 0 & 2.65 & 2.64 \\
\hline Sample 2 & 2 & 2 & 2.61 & 2.56 \\
\hline Sample 3 & 4 & 2 & 2.57 & 2.50 \\
\hline Sample 4 & 6 & 2 & 2.53 & 2.44 \\
\hline Sample 5 & 8 & 2 & 2.49 & 2.39 \\
\hline
\end{tabular}

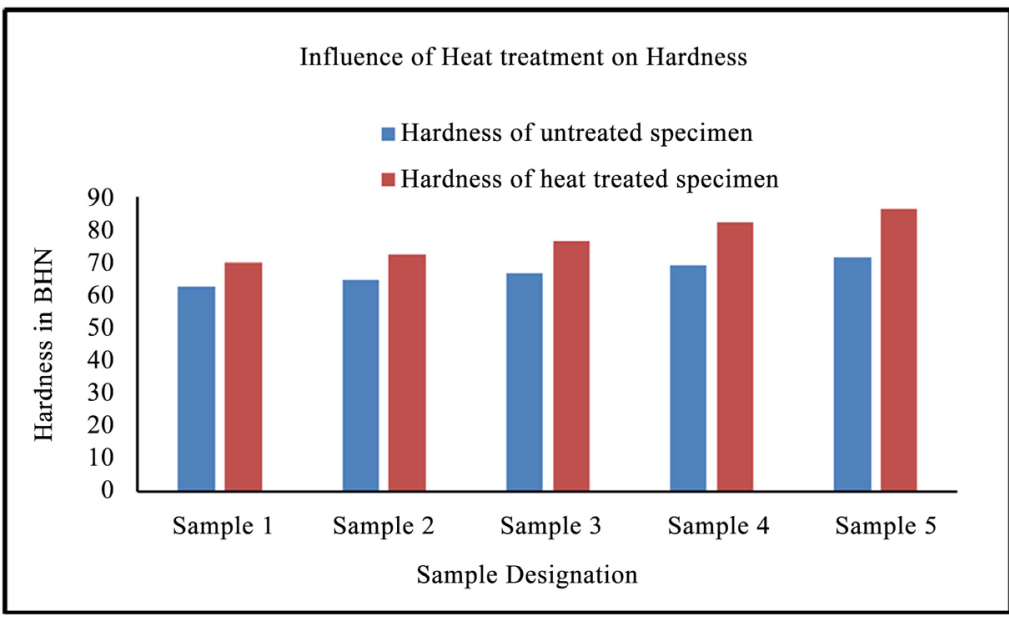

Figure 7. Influence of heat treatment on the hardness.

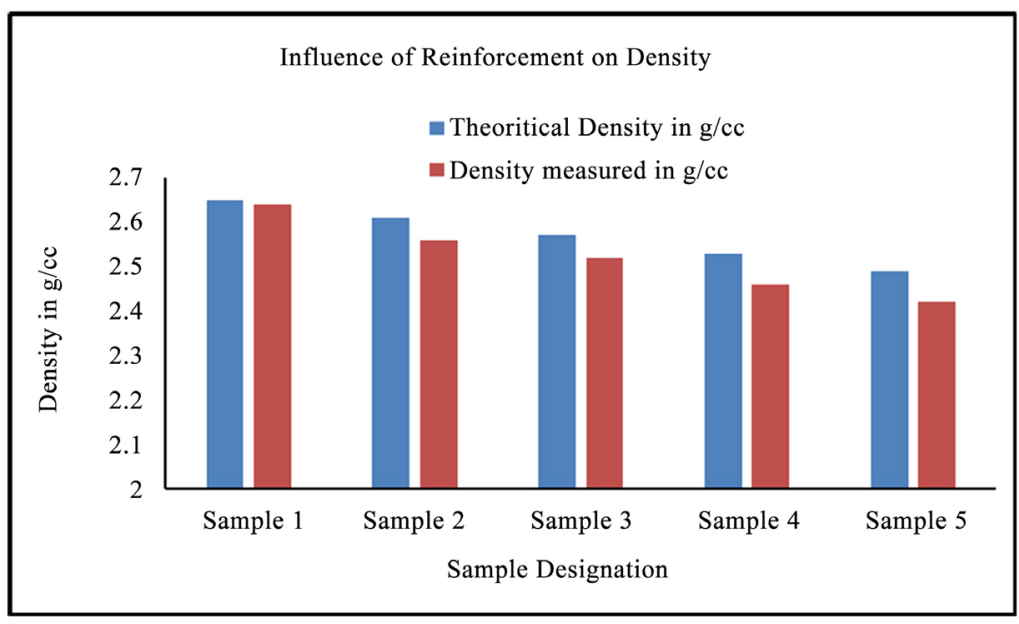

Figure 8. Influence of percent reinforcement on density. 


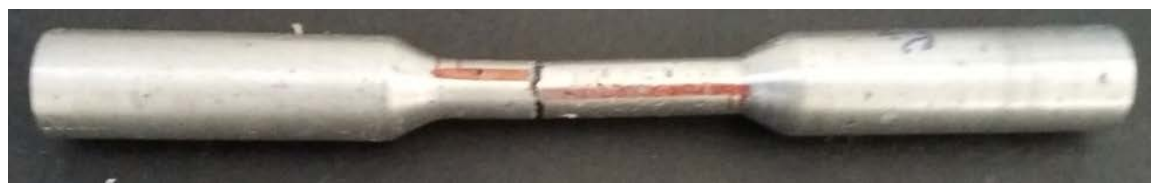

Figure 9. Specimen used for tensile test.

Influence of heat treatment on ultimate tensile strength

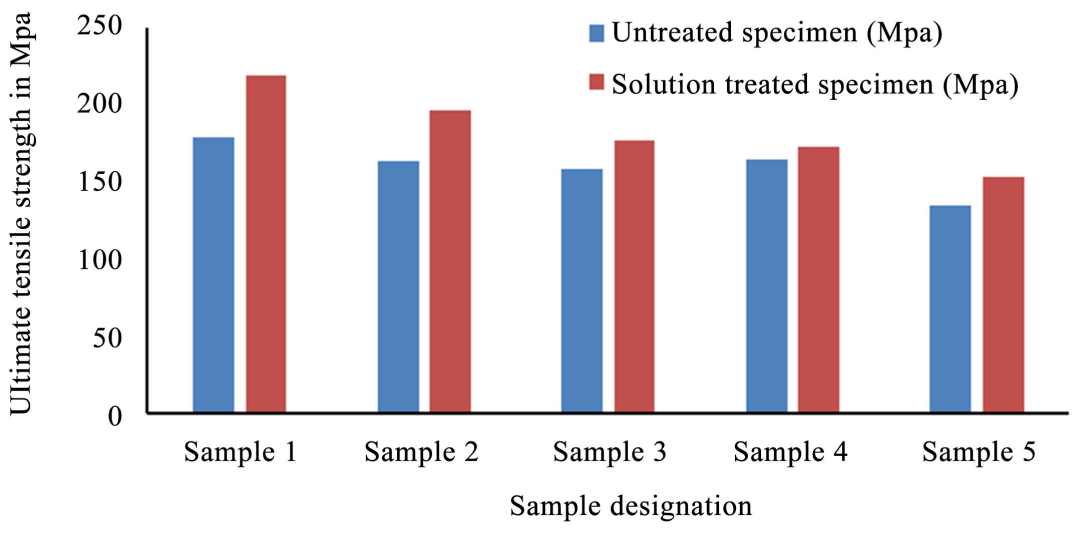

Figure 10. Influence of heat treatment on ultimate strength.

From the results of the tensile test, it can also be inferred that the ultimate tensile strength of solution heat treated specimens were found higher than untreated specimens.

\section{Percent Elongation}

The results of the tensile test is shown in Figure 11, From Figure 11, it is clear that the percent elongation of solution heat treated specimens were found higher when compared to untreated specimens.

The percent elongation of hybrid metal matrix composite containing 8 percent reinforcement found least. The percent elongation decreases with the increase of percent reinforcement.

\subsection{Corrosion Test}

The corrosion tests were carried out for HMMCs to evaluate the corrosion properties of the newly developed composite material. The corrosion tests carried out consists of the salt spray corrosion test and immersion corrosion test.

\subsubsection{The Salt Spray Corrosion Test}

The results of the salt spray corrosion test is shown in Figure 12. The results of the salt spray corrosion test reveal that the weight loss of the composites containing $6 \%$ cenosphere and $2 \%$ Red mud shown higher corrosion resistance when compared to $8 \%$ cenosphere and $2 \%$ Red mud. Increase in the percent of cenosphere shown significance role in enhancing the corrosion resistance. 


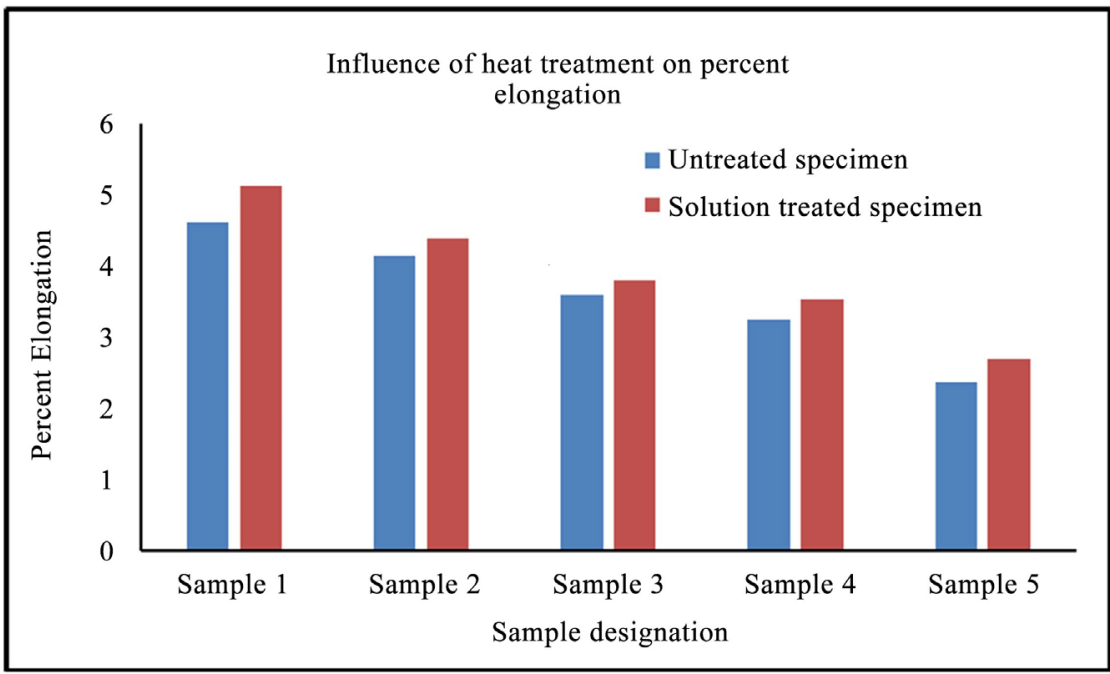

Figure 11. Influence of heat treatment on percent elongation.

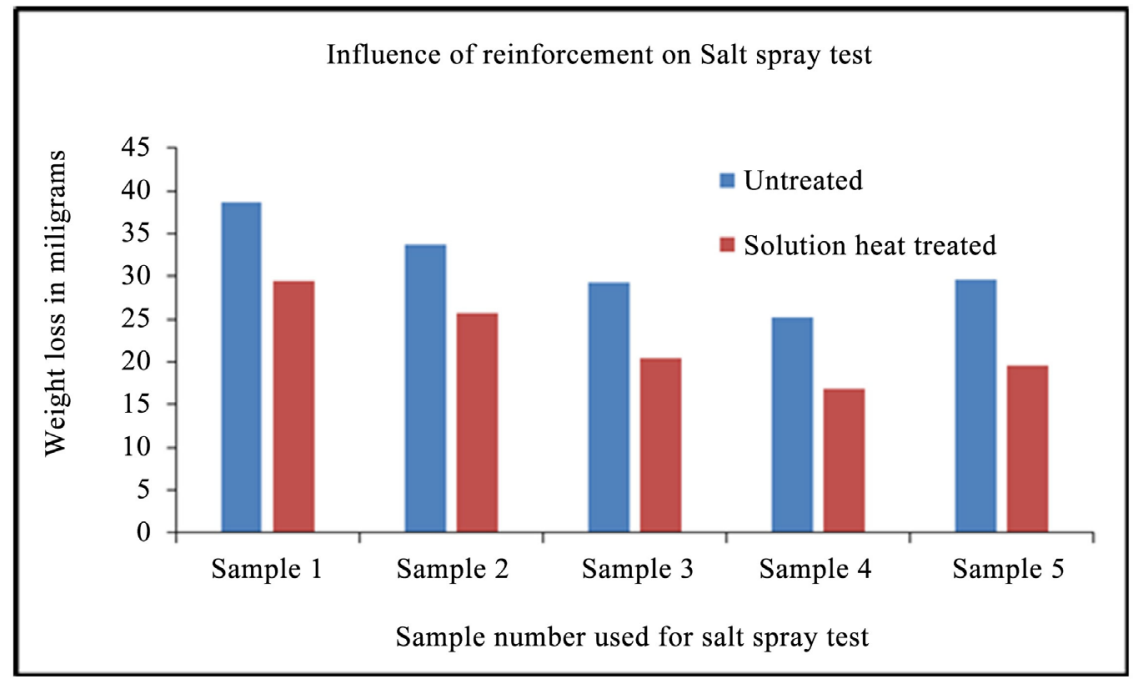

Figure 12. Influence of Reinforcement on weight loss during salt spray test.

From the analysis of the corrosion behavior of solution heat treated and untreated samples, it can be inferred that untreated composite material possesses lower corrosion resistance when compared to solution heat treated HMMCs. From the analysis of the corrosion test, it is clear that as percent cenosphere increases the resistance to corrosion of HMMCs follows ascending order till 6\% cenosphere, further addition of cenosphere results in a marginal increase of weight loss of the HMMCs material for both untreated and solution heat treated specimen.

\subsubsection{Immersion Corrosion Test}

Immersion corrosion tests were conducted as per ASTM G31-72 standards, the samples were machined to a size of diameter $28 \mathrm{~mm}$ and thickness $5 \mathrm{~mm}$, and weight loss for every 6 hours was measured, weight loss for a total of 48 hours was carried out and corrosion rates were determined. Every 6 hours the samples 
were taken out and weighed using an electronic weighing scale and Weight loss was recorded. This process was repeated for a total period of 48 hours, weight loss and corrosion rates were determined for every 6 hours. The images of the specimens subjected to immersion corrosion test on $\mathrm{NaCl}$ solution, before and after corrosion test are shown in Figure 13 and Figure 14 respectively. The images of the specimens subjected to immersion corrosion test on $\mathrm{NaOH}$ solution, before and after immersion corrosion test are shown in Figure 15 and Figure 16 respectively.

From, Figure 17 \& Figure 18, we can conclude that the weight loss is higher in the base material when it was subjected to identical corrosion environments. The weight loss of the HMMCs material followed descending order as percent filler increased till $6 \%$ cenosphere, further increase of cenosphere resulted with an increase in weight loss for both heat treated and untreated composites. Solution heat treatment of LM6 \& its composites resulted with marginal improvement in corrosion resistance.

From Figures 17-20, we can conclude that the weight loss of the LM6 and its composites containing varied percent cenosphere and constant percent red mud have shown reduced weight loss when it was immersed in $\mathrm{NaCl}$ when compared to $\mathrm{NaOH}$. The corrosion of sample containing $6 \%$ cenosphere and $2 \%$ red mud found least. Further, the rate of corrosion of the specimens when immersion corrosion test was carried out on $\mathrm{NaCl}$ than $\mathrm{NaOH}$ solution, it was found that the weight loss was lower in $\mathrm{NaCl}$ solution when compared to $\mathrm{NaOH}$ solution. The weight loss of the untreated specimens found higher than solution heat treated LM6, HMMCs having a different percentage of micro spheres and red mud particles. The corrosion resistance of solution heat treated specimens found higher when compared to LM6 base material. Formation of black film on the specimen surface was observed on both solution heat-treated and untreated specimens. The reason for forming of hydroxyl chloride layer on the specimens are the reason for specimens to possess black layer which eliminates further corrosion of the LM6 HMMCs.

The images of the specimens subjected to microstructural study are shown in Figures 21(a)-21(i). The photo micrograph of as cast HMMCs containing $0 \%$ reinforcement is shown in Figure 21(a). As-cast HMMCs containing 2\% red mud and $4 \%$ cenosphere is shown in Figure 21(b), as-cast HMMCs containing $2 \%$ red mud and $8 \%$ cenosphere is shown in Figure 21(c), HMMCs containing $0 \%$ cenosphere, $2 \%$ red mud and $4 \%$ cenosphere and $2 \%$ red mud and $8 \%$ cenosphere corrosion tested on $\mathrm{NaCl}$ solution are shown in Figure 21(d), Figure 21(e) \& Figure 21(f) respectively. HMMCs containing 0\% cenosphere, $2 \%$ red mud and $4 \%$ cenosphere and $2 \%$ red mud and $8 \%$ cenosphere corrosion tested on $\mathrm{NaOH}$ solution are shown in Figure 21(g), Figure 21(h) \& Figure 21(i) respectively.

The photo micrographs of the newly developed HMMCs are presented in Figures 21(a)-(i). From the SEM photo micrographs, it can be observed that the presence of both red mud and cenosphere particles in the newly developed hy- 
brid composite material are significant and the distribution of the cenosphere and red mud particles found even.

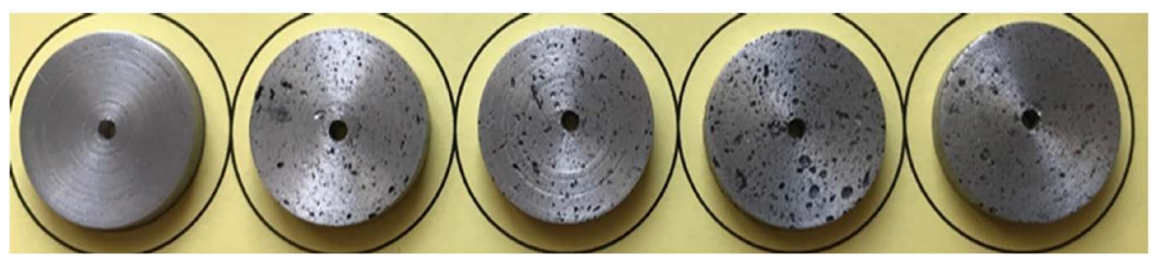

Figure 13. Specimen before immersion corrosion test.

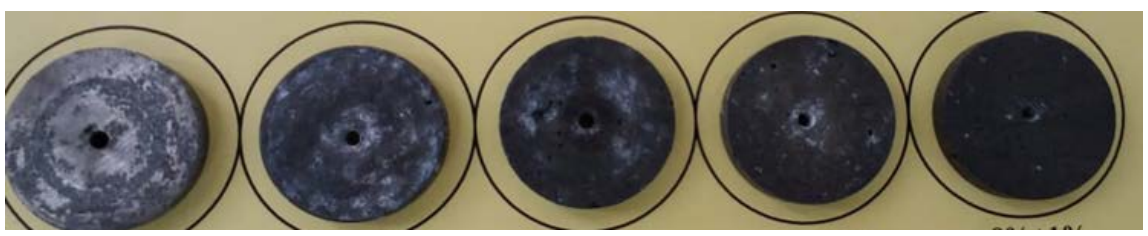

Figure 14. Specimen after immersion corrosion test30 days in $\mathrm{NaCl}$.

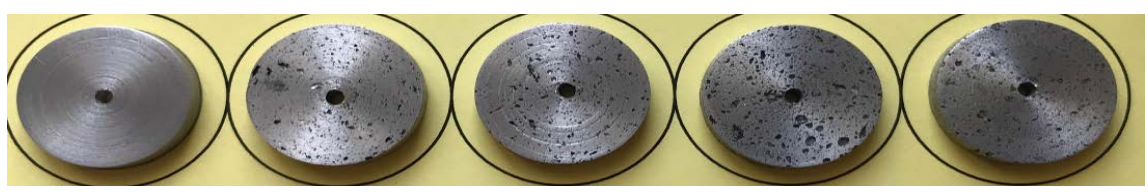

Figure 15. Specimen before immersion corrosion test.

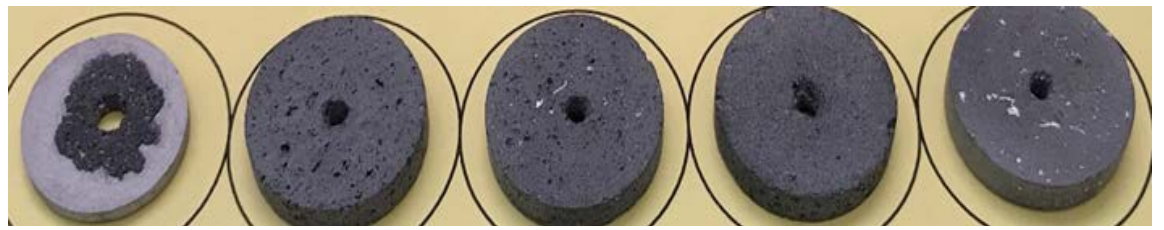

Figure 16. Specimen after 48 hours in $\mathrm{NaOH}$.

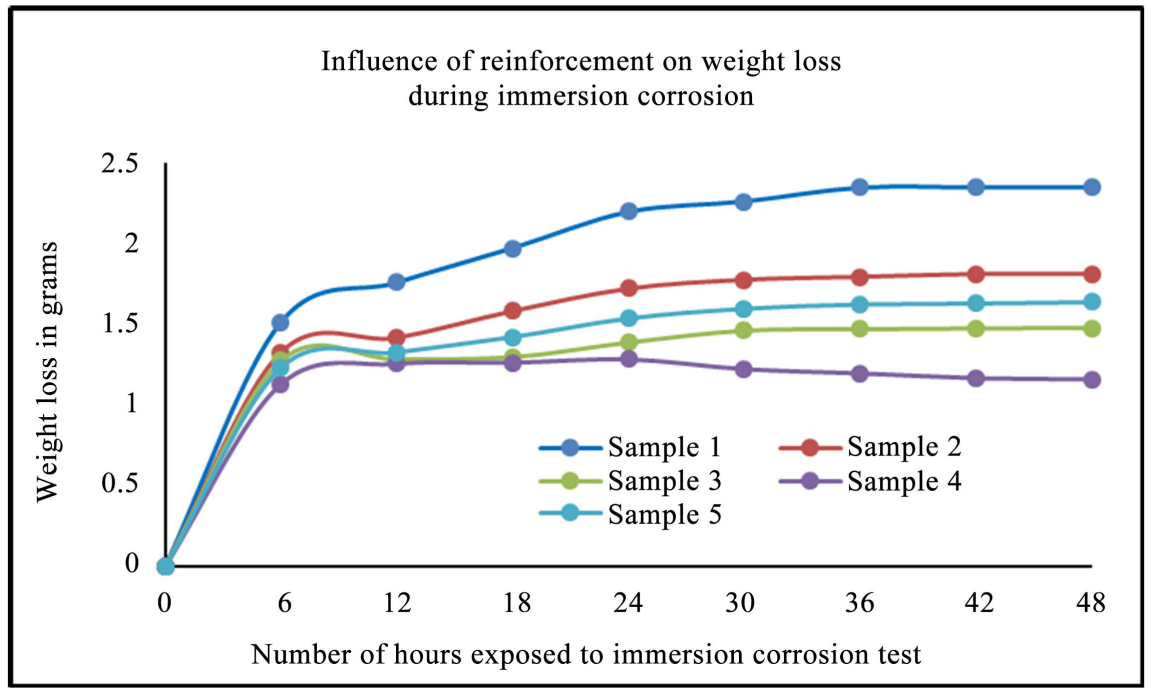

Figure 17. Influence of Reinforcement on weight loss of the untreated HMMCs material when the specimen was exposed to $\mathrm{NaOH}$. 


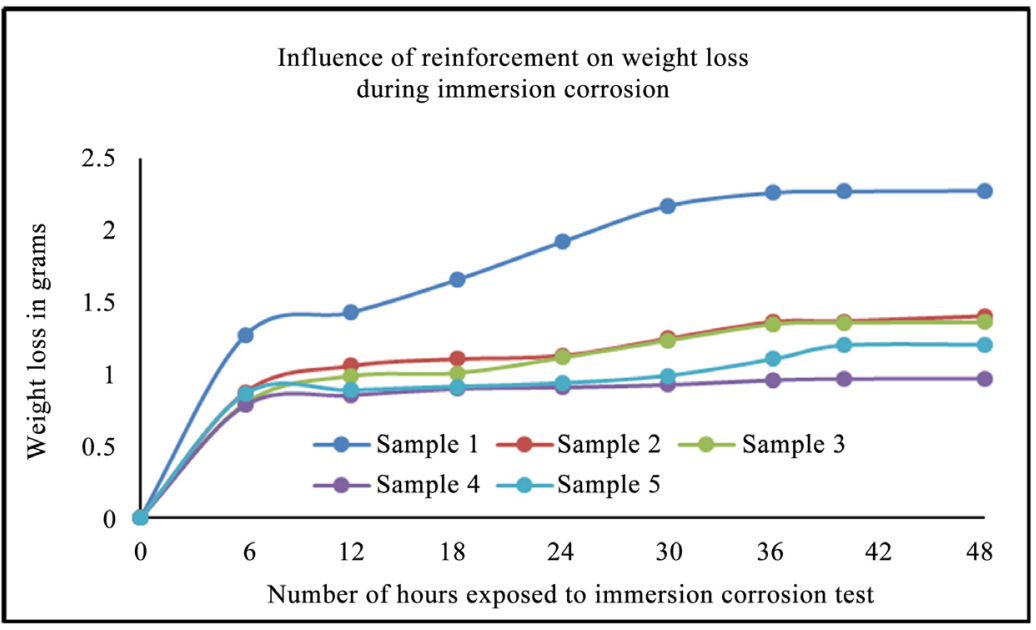

Figure 18. Influence of Reinforcement on weight loss of the Solution heat treated HMMCs material when the specimen was exposed to $\mathrm{NaOH}$.

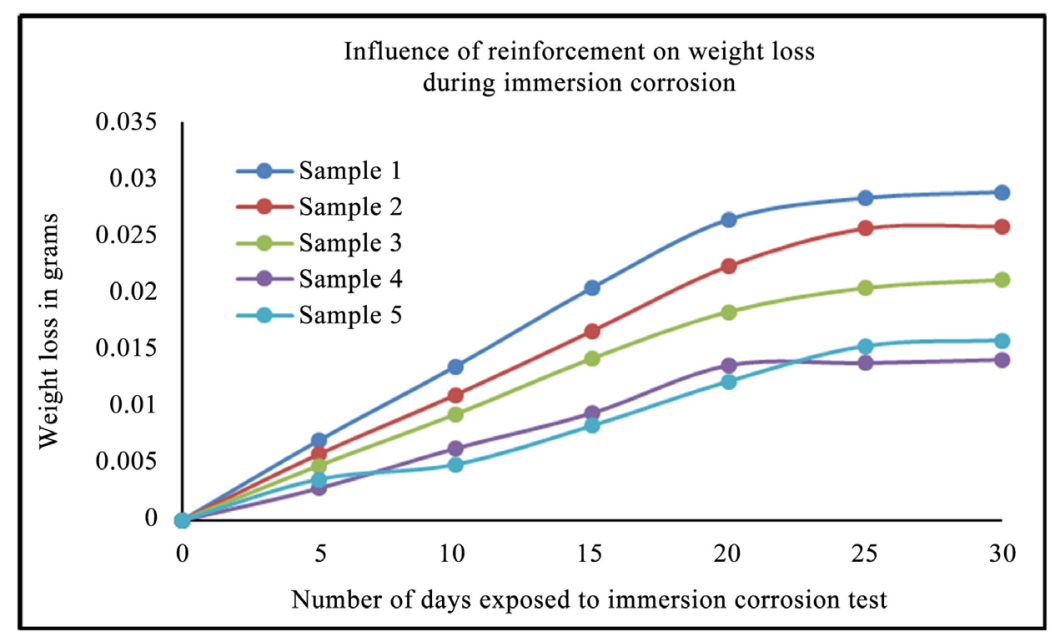

Figure 19. Influence of Reinforcement on weight loss of the untreated HMMCs material when the specimen was exposed to $\mathrm{NaCl}$.

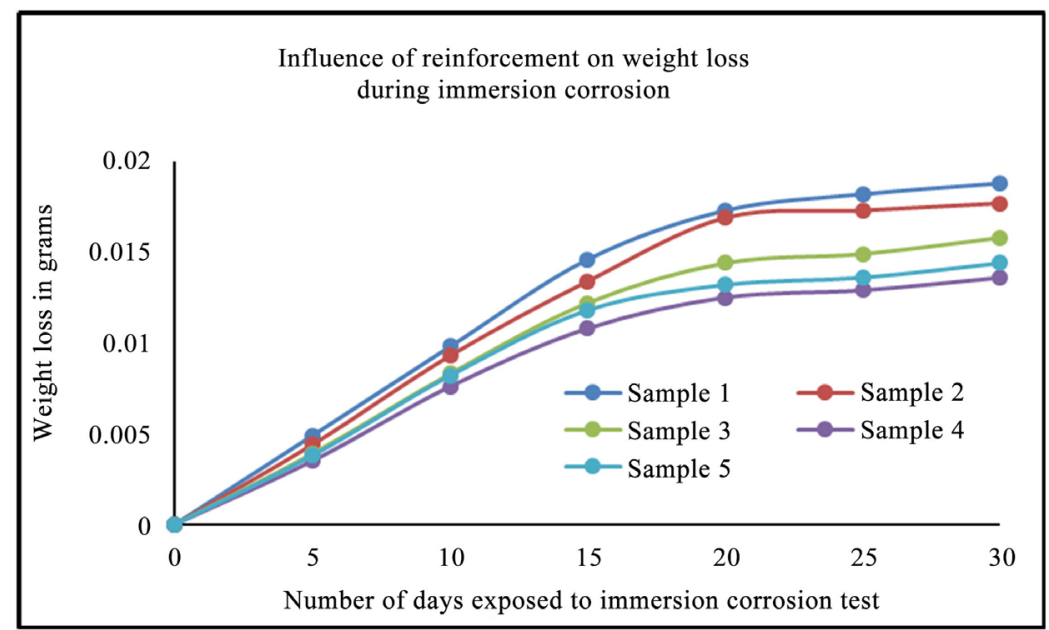

Figure 20. Influence of Reinforcement on weight loss of the solution heat treated HMMCs material when the specimen was exposed to $\mathrm{NaCl}$. 


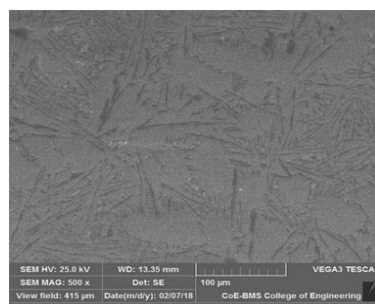

(a)

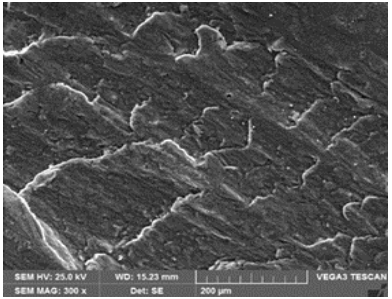

(d)

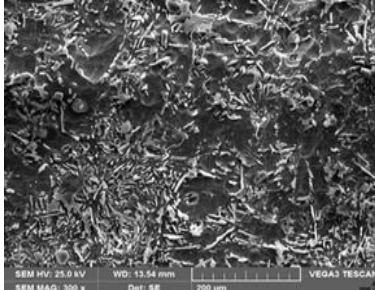

(g)

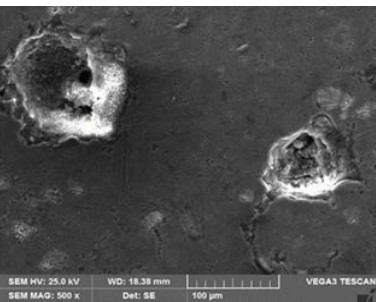

(b)

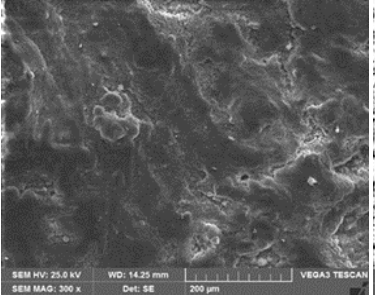

(e)

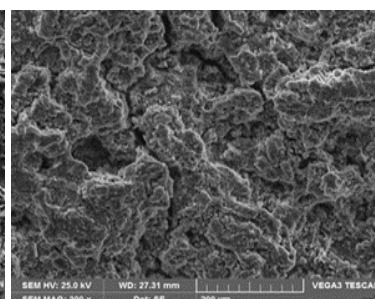

(h)

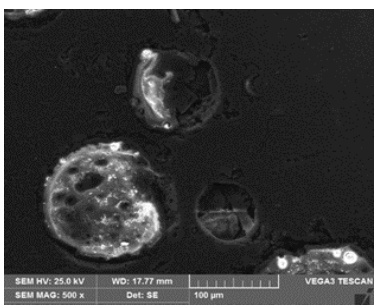

(c)

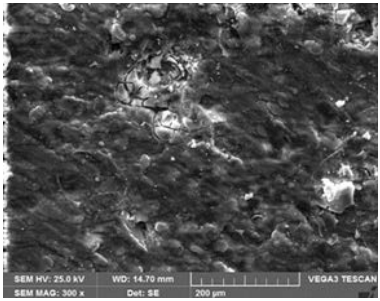

(f)

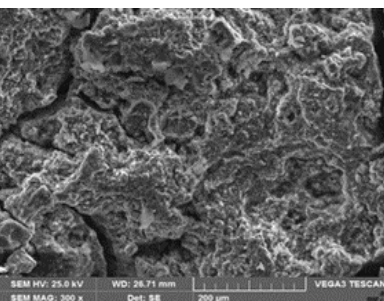

(i)

Figure 21. (a)-(i) Photo micrograph of LM6 HMMCs containing varied percent cenosphere and $2 \%$ red mud.

\section{Conclusions}

Hybrid metal matrix composites using LM6 as the matrix material, varied percent cenospheres and $2 \%$ red mud as reinforcing materials have been successfully fabricated using stir casting technique. The following conclusions were drawn from the various analysis.

- The hardness of the HMMCs were found higher than the base material. It is also observed that the hardness of the solution heat treated composites were found higher than untreated composites. Further, it is also observed that as the per-cent reinforcement increases the hardness of the HMMCs material increases.

- The density of the hybrid metal matrix composites were found lower than the base material.

- With the increase in the percentage of cenosphere and red mud, the density of the HMMCs material decreased.

- It is seen from the microstructural studies that there is a uniform distribution of cenosphere and Red mud in the matrix.

- The results of tensile test was revealed that there is a decrease in the ultimate tensile strength with the increase in cenosphere and red mud percentage.

- The percent elongation of HMMCs containing 8 percent reinforcement found least. The percent elongation decreases with the increase of percent 
reinforcement.

- Corrosion tests revealed that as percent cenosphere increases the corrosion resistance increases up to $6 \%$ addition of cenosphere, further addition of cenosphere results in marginal weight loss of the HMMCs material for both untreated and solution heat treated.

- The weight loss of the HMMCs material followed descending order as percent reinforcement increased till $6 \%$ cenosphere, further increase of cenosphere resulted with an increase in weight loss in both heat treated and untreated composites. Solution heat treatment of LM6 \& its HMMCs resulted with marginal improvement in corrosion resistance.

- Immersion corrosion test was carried out for both $\mathrm{NaCl}$ and $\mathrm{NaOH}$ solutions. From the corrosion test results it can be inferred that when $\mathrm{NaCl}$ was used the weight loss found lower than $\mathrm{NaOH}$ solution. The weight loss of the untreated specimens were found higher than solution heat treated LM6, HMMCs having a different percentage of micro spheres and red mud particles.

- The newly developed HMMCs material could be used as a replacement for monolithic materials used in the automobile sector.

\section{Conflicts of Interest}

The authors declare no conflicts of interest regarding the publication of this paper.

\section{References}

[1] Ravikumar, D.V., Seenappa, Asha, P.B. and Prakash Rao, C.R. (2018) Influence of Percent Filler on Tensile, Impact Strength and Wear Properties of the Al7075-Cenosphere Composites. Materials Today Proceedings, 5, 11697-11708. https://doi.org/10.1016/j.matpr.2018.02.139

[2] Ravikumar, V., Prakash Rao, C.R., Poornachandra and Suresh, R. (2018) Corrosion and Wear Studies on LM6 Grade Aluminium-Cenosphere Composites-An Experimental Approach. Materials Today proceedings, 5, 11667-11677. https://doi.org/10.1016/j.matpr.2018.02.136

[3] Bharat, V., Prasad, B.D. and Venkateswarlu, K. (2017) Effect of Beryllium Aluminum Cyclosilicate on Thermal Expansion Behavior of Al-Based Composites. Journal of Minerals and Materials Characteriszation and Engineering, 5, 140-152. https://doi.org/10.4236/jmmce.2017.53012

[4] Prakash Rao, C.R. Bhagyashekar, M.S. and Viswanath, N. (2014) Machining Behavior of Al6061-Fly Ash Composites. Procedia Materials Science, 5, 1593-1602. https://doi.org/10.1016/j.mspro.2014.07.347

[5] Prakash Rao, C.R., Poornachandra, Kiran, R. and Asha, P.B. (2016) Influence of Machining Parameters on Cutting Tool Life While Machining Aluminum Alloy Fly Ash Composite. IOP Conference Science and Engineering, 149, 012157. http://iopscience.iop.org/article/10.1088/1757-899X/149/1/012157/pdf

[6] Rajan, T.P.D., Pillai, R.M., Pai, B.C., Satyanarayana, K.G. and Rohatgi, P.K. (2007) Fabricationand Characterisation of Al-7Si-0.35Mg/fly Ash Metal Matrix Composites Processed by Different Stir Casting Routes. Composites Science and Technol- 
ogy, 67, 3369-3377. https://doi.org/10.1016/j.compscitech.2007.03.028

[7] Suresh, N., Venkateswaran, S., Nagaraju, G. and Seetharamu, S. (2014) Studies on the Mechanical and Wear Properties of Al-Si Alloy-Copper Coated Ceramic Microsphere Composite. Journal of Science, 4, 313-320.

[8] Prakash Rao, C.R., Bhagyashekar, M.S., Rajagopal, M.S. and Veda Vyasa, M. (2018) Influence of Edge Condition of Cutting Tool on Cutting Force and Surface Roughness While Machining Aluminum-Fly Ash Composites. Materials Today. Proceedings, 5, 11655-11666. https://doi.org/10.1016/j.matpr.2018.02.135

[9] Veeresh Kumar, G.B., Rao, C.S.P., Selvaraj, N. and Bhagyashekar, M.S. (2010) Studies on Al6061-SiC and Al7075-Al2O3 Metal Matrix Composite. Journal of Minerals and Materials Characterization and Engineering, 9, 43-55. https://doi.org/10.4236/jmmce.2010.91004

[10] Ravikumar, D.V., Seenappa, Prakash Rao, C.R. and Bharat, V. (2018) Corrosion Behavior of Cenosphere Reinforced Al7075 Metal Matrix Composite-An Experimental Approach. Journal of Minerals and Materials Characterization and Engineering, 6, 424-437.

[11] Zhang, Q., Zou, L.C., Zhu, X., Lin Y.F. and Wu, G.H. (2014) Interfacial Microstructure of Cenosphere Fly Ash/Al Composites. Composite Interfaces, 21, 353-357. https://doi.org/10.1080/15685543.2014.878832

[12] Ananda Kumar, M.G., Seetharamu, S., Nayak, J. and Satapathy, L.N. (2014) A Study on thermal Behavior of aluminum Cenosphere Powder Metallurgy Composites Sintered in Microwave. Procedia Materials Science, 5, 1066-1074.

http://creativecommons.org/licenses/by-nc-nd/3.0/

[13] Nguyen, Q.B., SharonNai, M.L., Nguyen, A.S, Seetharaman, S. and Gupta, M. (2016) Synthesis and Properties of Light Weight Magnesium-Cenosphere Composite. Material Science and Technology, 32, 923-929.

[14] Quader, S.M., Murthy, B.S. and Reddy, P.R. (2016) Processing and Mechanical Properties of $\mathrm{Al}_{2} \mathrm{O}_{3}$ and Red mud Particle Reinforced AA6061 Hybrid Compoosites. Journal of Minerals and Materials Characteriszation and Engineering, 4, 135-142. https://doi.org/10.4236/jmmce.2016.42013

[15] Rao, V.R., Ramanaiah, N. and Moulana, M. (2016) Mechanical and Tribological Properties of AA7075-Tic Metal Matrix Composites under Heat Treated (T6) and Cast Conditions. Journal of Material Research and Technology, 5, 377-383.

[16] Sreenivas Rao, K.V., Anilbakasha, K.C. and Girishaa, K.G. (2017) Effect of Particle Size on Mechanical Properties of Al-RMp Metal Matrix Composites. Materials Today Proceedings, 4, 11154-11157.

[17] Kumarswamy, S.P., Vijayanath, K., Thankachan, T. and Muthukutti, G.P. (2017) Investigations on Mechanical and Machinability Behavior of Aluminum/Flyash Cenosphere/Gr Hybrid Composites Processed through Composting. Journal of Applied Research and Technology, 15, 430-441.

[18] Dwivedi, D.K., Sharma, R. and Kumar, A. (2013) Influence of Silicon Content and Heat Treatment Parameters on Mechanical Properties of Cast Al-Si-Mg Alloys. International Journal of Cast Metals Research, 19, 275-282. https://doi.org/10.1179/136404606X153867

[19] Akhil, K.T., Arulb, S. and Sellamuthuc, R. (2014) The Effect of Heat Treatment and Aging Process on Microstructure and Mechanical Properties of A356 Aluminum Alloy Sections in Casting. Procedia Engineering, 97, 1676-1682. http://creativecommons.org/licenses/by-nc-nd/3.0 
[20] Singh, R., Telang, A. and Das, S. (2016) Microstructure and Mechanical Properties of Al-Si Alloy in As-Cast and Heat Treated Condition. American Journal of Engineering Research, 5, 133-137.

[21] Babalola, B.J., Oluwatosinbodunrin, M., Borode, J.O. and Alaneme, K.K. (2013) Corrosion Charecteristics of As-Cast Aluminium Bronze Alloy in Selected Aggressive Media. Journal of Minerals and Materials Characterization and Engineering, 1, 245-249.

[22] Alaneme, K.K., Adewale, T.M. and Olubambi, P.A. (2014) Corrosion and Wear Behavior of Al-Mg-Si Alloy Matrix Hybrid Composites Reinforced with Rice Husk Ash and Silicon Carbide. Journal of Material Research and Technology, 3, 9-16.

[23] Alaneme, K.K. and Bodunrin, M.O. (2011) Corrosion Behavior of Alumina Reinforced Aluminium (6063) Metal Matrix Composites. Journal of Minerals and Materials Characterization and Engineering, 10, 1153-1165.

https://doi.org/10.4236/jmmce.2011.1012088

[24] Ramesh, D., Swamy, R.P. and Chandrashekar, T.K. (2013) Corrosion Behavior of $\mathrm{Al}^{6061}$-Frit Particulate Metal Matrix Composites in Sodium Chloride Solution. Journal of Minerals and Materials Characterization and Engineering, 1, 15-19. https://doi.org/10.4236/jmmce.2013.11003

[25] Chlistovsky, R.M., Heffernan, P.J. and DuQuesnay, D.L. (2007) Corrosion-Fatigue Behavior of 7075-T $\mathrm{T}^{651}$ Aluminium Alloy Subjected to Periodic Overloads. Journal of Fatigue, 29, 1941-1949. 